\title{
Exploration on the Implementation of Cross- specialty Practice Teaching Based on VBSE
}

\author{
YuCheng Geng \\ City College of Dongguan University of Technology \\ Dongguan, Guangdong, China \\ 94101351@qq.com
}

\begin{abstract}
The cross-specialty practice teaching of economics and management is an important way to realize the training goal of applied and compound talents. Based on VBSE, this paper analyzes the characteristics and teaching of cross-specialty practice in economics and management. The matching degree between professional-post-skill-student, teacher structure and job division has become a prominent problem that restricts the effect of practical teaching. Specific solutions are proposed for the dimensions of curriculum resource allocation, teacher team building, and curriculum management and evaluation. Through the exploration of process and path, it provides a multidimensional collaborative construction way for the reform of the practical teaching mode of cross-specialty in economics and management, which will effectively realize the integration of teaching of each specialty in economics and management, and is conducive to the establishment of the integrated teaching mode of cross-specialty in theory and practice.
\end{abstract}

Keywords-Cross-specialty; Practice teaching; VBSE; Teaching model

\section{INTRODUCTION}

In the big data environment, innovation drives industrial upgrading, economic and management expertise crisscrosses. At the same time, the demand for integration and application of cross-professional knowledge in post practice is expanding. Cross-specialty practice teaching aims to let students simulate actual business practice through task-driven and independent management process, and gradually cultivate professional competence and innovative thinking in "learning" and "doing". Based on the integration of business management, accounting, financial management, international trade and other business disciplines, the cross-specialty practice teaching platform gradually transits to the integration of Engineering practice, and integrates with innovation and entrepreneurship practice platform to provide auxiliary services for innovation and entrepreneurship projects[1]. Cross-specialty practice teaching is an important way to cultivate applied, compound and innovative talents. As a practical teaching platform for business management majors, VBSE realizes the integration of different majors and positions in the virtual business environment through role-playing, team competition and cooperation. However, VBSE teaching platform contains complicated logic

Educational cooperation and education project of the Ministry of Education, "xindao yun Financial Practice Teaching Base of City College of Dongguan University of Technology" (201801069071);

The Higher Education Teaching Reform Project of City College of Dongguan University of Technology: "Reform of Interdisciplinary Practical Teaching System Based on VBSE Virtual Business Social Environment";

The Key Course Project of City College of Dongguan University of Technology: "Comprehensive Business Practice". relations of teaching tasks and positions[2]. How to effectively plan the teaching process, realize classroom inversion and give full play to the integration advantages of the platform has become a difficult problem faced by the cross- specialty practice teaching process.

\section{Main Features of Cross-SPeCialty PRACtice TeAching IN ECONOMICS AND MANAGEMENT}

\section{A. Commercial ecological environment simulation}

Virtual simulation of business environment is the basis of practical teaching of economics and management. The platform support is needed for the deep integration of different majors and positions within the economics and management category. The integration of post, knowledge, skill and role is the basic requirement of compound and innovative talents training. Interdisciplinary comprehensive training is a comprehensive practical teaching course for economics and management majors in universities and colleges. By extracting the typical characteristics of different forms of organizations, the course builds a virtual business social environment, which enables trainees to integrate business simulation with real work and imitate it in the virtual market environment, business environment, government environment and public service environment, according to the actual job content, management process, business documents and business rules adapted to teaching objectives. True operation and business operation can carry out macro and micro management and multi-person collaborative simulation operation to train students' comprehensive executive ability, comprehensive decisionmaking ability and innovation and entrepreneurship ability, and cultivate students' overall awareness and comprehensive professional quality.

\section{B. Task likability.}

In the virtual simulation system, there is a complete logic chain between tasks, and the business decision-making behavior directly determines the supply, production and marketing process of the enterprise, and the financial situation and market trends affect the enterprise's decision-making results. Each link within the task requires two-way operation of online and offline operations. There are strict requirements on the logical relationship between offline order filling, online data processing and business operation, which complement each other and have strong likability requirements. In the 
virtual simulation system, there is a complete logic chain between tasks, and the business decision-making behavior directly determines the supply, production and marketing process of the enterprise, and the financial situation and market trends affect the enterprise's decision-making results. Each link within the task requires two-way operation of online and offline operations[3]. There are strict requirements on the logical relationship between offline order filling, online data processing and business operation, which complement each other and have strong likability requirements.

\section{The flexible and extensible teaching session.}

Cross-specialty practice teaching provides a good environment for the implementation of new teaching methods such as flipped classroom and inquiry learning. Teachers can choose job training tasks and increase or decrease teaching interaction links according to students' specialty allocation and task completion. In practice and training teaching, the learning process becomes a creative practice activity that one actively participates in. The emphasis is not on the final result, but on the process of completing the operation. Practice shows that in the process of practice and practice teaching, students can understand and grasp the knowledge and skills required by the curriculum, experience the hardship and fun of innovation, and cultivate the ability of analyzing and solving problems, communication and cooperation.

\section{Competition and cooperation.}

In a virtual business environment, strategic alliances are a common competitive state among business organizations. Teams will also cooperate in a fully competitive environment. Through the construction of effective experimental scenarios, students continuously explore the knowledge and skills of cross-specialty fields by applying the basic knowledge and skills of their specialty in practice, and realize the self-learning and integration of cross-specialty knowledge in the process of inquiry learning through on-the-spot job practice, so as to gradually enhance their comprehensive abilities and lay a foundation for the cultivation of innovation consciousness and entrepreneurship.

\section{MAIN TEACHING LINKS}

The implementation process of cross-specialty practice teaching of economics and management on the platform of "VBSE" can be divided into three links: teaching preparation, fixed operation teaching, and independent operation teaching.

TABLE I. TASK COMPLETION STATISTICS OF MAIN TEACHING LINKS

\begin{tabular}{|c|c|c|c|}
\hline No. & Link & $\begin{array}{c}\text { The teaching } \\
\text { way }\end{array}$ & $\begin{array}{c}\text { Task completion } \\
\text { ratio }\end{array}$ \\
\hline 1 & teaching preparation & team-creation & $100 \%$ \\
\hline 2 & fixed operation teaching & $\begin{array}{c}\text { on-the-job } \\
\text { training }\end{array}$ & $98 \%$ \\
\hline 3 & $\begin{array}{c}\text { independent operation } \\
\text { teaching }\end{array}$ & $\begin{array}{c}\text { team } \\
\text { competition }\end{array}$ & $92 \%$ \\
\hline
\end{tabular}

Compared with regular practice teaching, VBSE teaching preparation process is more complicated. At this stage, we should first plan the allocation of majors, plan the number of students and ensure the proportion of majors. Secondly, it is necessary to complete the construction of teaching classes and post planning to ensure the proportion of teaching classes and posts. Best of all, we should fully estimate the market situation and reasonably set up the market capacity. Through the systematic simulation of typical units, departments and posts in the real business social environment, the students can experience the pre-job training, recognize and familiarize themselves with the contents and characteristics of different organizations and positions in modern business society, and cultivate the students' comprehensive executive ability, comprehensive decision-making ability and innovative ability needed to engage in business management, so as to make them have overall awareness and comprehensive professional quality, to solve the problem of college students' internship ${ }^{[4]}$

The fixed management stage is the key core of crossspecialty comprehensive practice teaching. At this stage, the teacher should organize the division of labor according to the task of pushing and complete the operation training of each post. The effective task completion rate of this link is about 98\%. This section should briefly introduce the system operation process, and also summarize the key core tasks, so that students can clearly define the relationship between posts. The teaching effect of this process directly determines the effect of cross-specialty composite application, and the process is directly related to the degree of specialty matching, which has strong flexibility. The Independent operation stage is an important part of the cultivation of compound skills and innovative thinking. This link is carried out on the basis of familiarity with basic processes and job responsibilities in the fixed operation phase. In this stage, the business is completed through team competition and cooperation in a complete virtual simulation environment. The strategies of procurement, production, sales, and finance are all determined by the students themselves, and the teachers only play a supporting role. The effective completion rate at this stage is about $92 \%$, and the unfinished part is mainly concentrated on comprehensive financial work such as cost accounting and report processing.

\section{The MAin PROBlems IN THE IMPLEMENTATION OF CROSS- SPECIALTY PRACTICE TEACHING}

\section{A. Lack of top-level design, "Major-post-student" with Low Matching Degree.}

The biggest conflict in the implementation of crossspecialty practice teaching of economics and management comes from the lack of top-level design, and the unreasonable overall coordination and planning of different departments and majors[5]. The process of defining and connecting the professional span boundary is the process of personnel training plan making. Economics and management class of each major to open cross-specialty practice teaching semester arrangement, class hour provisions should be coordinated as a whole. The most prominent problem is that the cross-specialty practice teaching process based on VBSE has a great dependence on the needs of accounting and financial management students. In terms of specialty allocation, we must balance the matching degree between accounting and non-accounting majors in order 
to promote the high integration and unification of "major-poststudent". In terms of specialty and post allocation, we should follow the principle of proper separation and cohesion between posts and majors, so as to achieve the teaching purpose of cross-specialty integration.

\section{B. Improving the Teaching Level of Cross-specialty Teachers}

Although all majors of economics and management have certain commonness in knowledge system, the differences among majors are still obvious. In the open business environment of virtual simulation, teachers are required to have a solid theoretical foundation and practical application ability, and more importantly, teachers are required to have an extended ability across professional skills. Professional post training can only solve specific post problems. In a complete business environment, the high integration of cross-specialty knowledge has gone beyond the scope of teachers' own professional knowledge, and teachers' knowledge and ability cannot meet the requirements of cross-specialty practice teaching. For example, the purchasing and selling process of bidding involves many links such as procurement, bidding, bid opening, sales, logistics, tax, etc. As far as the current professional teaching is concerned, there are few links that can cover all aspects of the process. Therefore, how to maximize the teacher's professional knowledge span level and application skills in cross-specialty practice teaching is an important problem faced by the management of cross-specialty practice.

\section{Conflict between Professional Post Training and Compound Skills Training}

The cross-specialty practice teaching platform of economics and management based on "VBSE" involves more than 10 industries and nearly 50 job roles in content. In teaching organization, professional training by post is a common form. This model can effectively solve the guidance and practice of knowledge and applied skills in various positions, and can guarantee the orderly development of practical training courses. However, this model takes the post as the unit to train, emphasizes the application of post skills, but neglects the communication and information transmission between posts, which is not conducive to the cultivation of compound skills. For example, the role of production planner, its main task is to prepare the master production plan table and the net material demand table. If only job training is conducted for the compilation of the form, it will inevitably split its interaction with many posts such as sales, warehouse management, workshop management, procurement and so on. Let the students see the trees but not the forest. It is not conducive to the collaboration within the group, but also runs counter to the training objectives of compound talents.

\section{Unbalanced Division of Tasks and Loss of Motivation among Students.}

In the process of cross-specialty practice teaching of economics and management, teachers assign training tasks according to virtual dates. Different positions have different assignments on different virtual dates. Some posts may have more tasks, while some posts are more relaxed or even have no tasks. For example, cost accounting posts have few tasks at the beginning of the month and in the daily business process. A large number of cost calculation and transfer processes are concentrated at the end of the period, and cost collection and allocation must be completed in a virtual day. Task concentration is more obvious. In the setting of posts in peripheral units, the uneven distribution of tasks is particularly evident. The tasks of banks and service companies are especially huge, while those of customs and import and export trading companies are less. The unbalanced distribution of tasks directly affects the work enthusiasm of students. In addition, the uneven distribution of tasks, such as the concentration of tasks in some key positions, will also affect the progress of the overall curriculum to a certain extent.

\section{E. Fuzzy Evaluation Mechanism}

In the process of team competition, the choice of evaluation criteria will directly affect the business decision-making behavior of each team[6]. If the effective order quantity is used as the standard, a large amount of credit sales and purchase behavior will be generated, which will increase the financial risk of the enterprise; if the profit is the standard, accurate cost and cost indicators are needed, but in the self-management stage, the supply and sales of each group are different. The lack of a unified supervision and correction mechanism is very difficult to achieve. In addition, the professional allocation will also have a greater impact on the establishment of evaluation criteria and mechanisms. There are obvious differences in task completion tendency among students of different majors in the process of business operation. There is no unified standard for the evaluation of multi-disciplinary ability, and the overall evaluation mechanism is relatively vague. The decisionmaking tendencies of teams participating in competition will vary greatly in different evaluation criteria.

\section{MAJOR MEASURES TO IMPROVE THE QUALITY OF CROSS- SPECIALTY PRACTICE TEACHING OF ECONOMICS AND \\ MANAGEMENT}

\section{A. Doing a Good Job of Top-level Planning, Unified Coordination of Curriculum Allocation}

There are many majors involved in the cross-specialty practice teaching of economics and management. To make a good top-level planning, we should start with the personnel training program, clarify the specialty division, semester arrangement, credit and hours setting, etc. The rational allocation of "major-skill-post-student" should be done well from the root. It is required that under the premise of meeting the national teaching quality standards, the training programs of talents of different specialties should be jointly explored to explore the boundary of specialty span. Secondly, it is necessary to set up separate cross-specialty practice teaching organization units of economics and management, purchase teaching resources, organize teaching tools, and complete batch organization construction in the system. At this stage, the most important thing is to rationally plan the number of posts, the number of organizations, the application and application of virtual accounts according to the number of students in each major. Finally, through the unification and coordination of the batch structure and time of courses offered by various majors, 
the integration of professional span can be fully realized and conflicts with other courses can be avoided. Through many years of practice teaching summary, an effective coordination mode is to set up specialized teaching units and coordinate resource allocation and curriculum organization within the framework of talent training program.

\section{B. Promoting Cross-specialty Ability and Establishing High- quality Teaching Team}

Cross-specialty practice teaching puts forward higher requirements for teachers' professional knowledge and teaching mode, and it is required to build a distinctive practice teaching team. First of all, we should strengthen the construction of "double-qualified" teaching staff, formulate a practical teaching team training plan for college professional leaders, backbone teachers, enterprise certification instructors, enterprise authorized instructors and field expert groups, and participate in enterprise cooperation projects and professional teaching parties through professional, industry skills training, enterprise post practice. In the form of law training, teachers' professional ability of practical teaching, practical teaching method ability, informationization ability of practice teaching, professional innovation ability, practical curriculum design ability and curriculum textbook research and development ability are mainly trained.

To strengthen the construction of teaching team; build a reasonable and practical "double-qualified" teaching team, teachers are encouraged to take part-time jobs in enterprises through training and learning, and school teachers enter enterprises. Teachers are encouraged to take part-time jobs in enterprises or relevant industries or professional skills certificates. Excellent staffs of enterprises are employed as consultants, guest teachers and part-time teachers. Practical teaching teams of double-tutorial system are implemented to improve students' applied skills and composite practical abilities in the form of project-driven.

\section{Doing a Good Job of Post Integration and Realize the Goal of Compound Skills Training}

Job integration is an important means to realize the matching ratio between job and number of students, and it is also the foundation of compound skill training. Firstly, the number of organizational structure of the unit should be selected according to the specialty. There are too many positions in the core manufacturing enterprises in the course of Comprehensive Training of Enterprise Operation Simulation, which basically covers the types of jobs that students may come into contact with in the future. However, in the process of teaching, students can only apply for one of the positions with a certain account number for various business operations. Some students hope to know more about other jobs in their spare time. This function cannot be realized by the teaching platform, and need to seek other means to solve it.

This part is mainly targeted at the peripheral units, such as customs, import and export companies, Industrial and Commercial bank of China, and chain enterprises. Secondly, the job organization should be determined on the basis of the number of students. This part mainly aims at manufacturing enterprises, and reasonably determines the number of organizational units, post and task combination and other contents. In the process of organizational setting and post combination, the adaptation principle of specialty and skill must be followed to ensure the effective cultivation of compound skills. In the process of post integration, teachers should take into account the logical relationship between supply, production and marketing as well as the support of administrative assistant units to the real enterprises, so as to avoid unreasonable allocation simply to match the number of students. In addition, bidding companies, chain enterprises and import and export units can adjust the market capacity, although they have less business volume. Teachers should pay attention to the operation of such posts in order to ensure the antagonistic needs of the overall training.

\section{Constructing a Scientific and Reasonable Flexible Evaluation Mechanism}

The formulation of flexible evaluation mechanism should be based on the professional allocation of each batch of training, taking into account the operating performance, asset stock, profit situation, achievement reporting and other parameters, and setting a comprehensive evaluation weight index. The selection of comprehensive evaluation indicators must avoid the thinking of emphasizing financial performance and ignoring the improvement of team's composite ability. It should have clear evaluation basis and give evaluation mechanism some flexibility. Through the flexible evaluation mechanism, the management decision-making behavior of each team can be correctly guided, and the assistant guarantee for the cultivation of compound and innovative talents can be provided.

In addition, cross-disciplinary integrated practice teaching involves team competitive confrontation, and a more detailed conflict coordination and resolution mechanism should be formulated to ensure that teams can participate in the operation in an open environment in a reasonable and orderly manner. Finally, the teachers' evaluation and team evaluation must be objective, fair and transparent. The teaching activities of the interdisciplinary comprehensive experimental center are not specific to specific specialties, but focus on the training of the workflow of enterprises, external environment of enterprises, key positions and typical tasks. It requires not only the experience of simulation environment, but also the decisionmaking of enterprise management. It also requires the task of corresponding management process to achieve the practical teaching goal of trinity of decision-making, execution and experience.

\section{E. Comprehensive use of various teaching methods}

In the era of big data, information technology constantly drives the reform of practical teaching methods for economics and management majors. More intelligent mobile terminal equipment, internet technology, fragmentation, intuitive information transmission has become an important form of knowledge dissemination. The way students receive knowledge has been changing, and the channels of exploring knowledge have been expanding. This requires colleges and universities to actively change their concepts, innovate teaching methods and 
establish a more open and equal new ecology of practical teaching. We should design the teaching process rationally and choose teaching strategies flexibly according to the requirements and characteristics of professional practical skills. In view of the characteristics of professional skills and the dynamic changes in the process of practice, targeted teaching strategies are selected in advance. In order to ensure the dynamic interaction of the process, open teaching links should be flexibly set up under the rules of accounting policies and information acquisition channels on the Internet. Second, the practical teaching process should be good at applying information-based teaching methods, weakening the leading role of teachers in practical teaching, advocating differentiated personality development, and providing space for students' innovative thinking practice while assisting in solving problems.

Inquiry teaching mode is an effective way to cultivate innovative thinking and entrepreneurial consciousness. The application of inquiry teaching mode should be combined with the students' professional competence level, and there are some cross-disciplinary open-ended problems within the scope of the syllabus. For some practical teaching with strong specialty, it is necessary to scientifically design the stage guidance syllabus, which conforms to the law of students' learning and cognition. In the course of curriculum design, we should correctly handle the logical relationship between business and finance, and the relationship between teachers, students and information technology. In the process of integrating theory with practice, we should fully consider the differences of teaching objects and objectives, and implement different inquiry modes. Practical teaching oriented by multi-disciplinary and innovative ideas often needs a prescriptive inquiry mode, i.e. student team cooperation as the main body, making plans, implementing programs, and summarizing the results of the events.

\section{SUMMARY}

The practice teaching of management based on VBSE provides a good platform for the training of applied and compound talents. Perfect curriculum design and teaching mode are more conducive to the realization of the trinity of experience, decision-making and implementation of practical teaching objectives, and to ensure the achievement of the goal of personnel training.
- Relying on the talent training program to make a good overall planning is the premise of management crossspecialty practice teaching, which can effectively guarantee the realization of cross-specialty practice purpose.

- The allocation of majors, posts and students' skills is the core element of practical teaching. It should be based on the cultivation of professional skills and follow the basic principles of moderate separation and effective convergence.

- The improvement of teachers' practical skills is the key to ensure the cross-specialty practice teaching of economics and management. While teachers' practical level should be extended to cross-specialty level, they should make full use of information technology to constantly innovate teaching methods.

- The core purpose of cross-specialty practice teaching of economics and management is to gradually cultivate innovative thinking and entrepreneurship through team competition and cooperation in the virtual simulation business environment system. It is necessary to highlight students' principal position in practical teaching.

\section{REFERENCES}

[1] G.S.Akerlind, Separating the teaching from the academic: Possible Unintended consequences. Teaching in Higher Education, vol. 16, 2016, pp. 171-175.

[2] Chalmers, D, Progress and challenges to the recognition and reward of the scholarship of teaching in higher education. Higher Education Research \& Development, vol.1, 2017, pp. 25-38.

[3] George, M. A., and P. Davis-Wiley. Teaching a graduate course. Case study: A clinical research course. College Teaching, vol.48(2), 2015, pp.75-80.

[4] Seabury, M. B., and K. A. Barrett. Creating and maintaining team-taught interdisciplinary general education. New Directions for Adult and Continuing Education, vol.87(Fall), 2014, pp. 15-24.

[5] Goodenow, C. Classroom belonging among early adolescent students: Relationship to motivation and achievement. Journal of Early Adolescence, Vol.11, 2013, pp. 21-43.

[6] Erb, T.and Stevenson, C. From faith to facts: Turning Points in actionWhat difference does teaming make?, School Education Journal, Vol.20(3), 2018, pp.47-50. 